\title{
BMJ Open Quality Quality improvement report: setting up a staff well-being hub through continuous engagement
}

\author{
Aaisha Saqib (D) , ${ }^{1}$ Tarannum Rampal ${ }^{2}$
}

To cite: Saqib A, Rampal T. Quality improvement report: setting up a staff well-being hub through continuous engagement. BMJ Open Quality 2020;9:e001008. doi:10.1136/ bmjoq-2020-001008

Received 4 May 2020 Revised 6 August 2020 Accepted 12 August 2020

Check for updates

(c) Author(s) (or their employer(s)) 2020. Re-use permitted under CC BY-NC. No commercial re-use. See rights and permissions. Published by BMJ.

${ }^{1}$ Royal College of Physicians Chief Registrar, Medway Maritime Hospital, Gillingham, UK

${ }^{2}$ Prehabilitation services lead, Medway Maritime Hospital, Gillingham, UK

Correspondence to

Dr Aaisha Saqib;

aaishasaqib@nhs.net

\section{ABSTRACT}

The coronavirus pandemic has presented a new set of challenges for the frontline National Health Service staff. It is not only the long working hours but also the uncertainty and increase in patient mortality that has affected mental health and staff well-being. Hospitals all around the country have rightly responded with various well-being initiatives to help their staff such as wobble rooms and developing online resources. Our vision was to set up a safe space for staff away from clinical noise to enable and encourage mindfulness and psychological resilience through a calm and serene environment. We used the continuous quality improvement methodology and administered an initial needs assessment survey to see if our trust staff will be interested in having such a space. Within our team, we managed to secure a place, and used donations to hospital charity and set up a space within a week. Since opening the hub, we have had excellent feedback from various staff groups. Immediate feedback was obtained using emoji stickers asking for feelings before and after visit. A mood board was put up allowing anonymous expression of feelings. Delayed feedback was requested using a repeat survey. We believe that while there is a lot of talk about well-being and an increasing number of resources being offered electronically, the need for a neat and quiet space cannot be overlooked. We collect feedback on a weekly basis and adapt the space to meet the needs of staff. Long-term impact of such spaces will be reassessed at a later stage.

\section{AIM}

Setting up a staff well-being hub-a designated 'positive space' for staff to help them detox and recuperate during the COVID-19 pandemic.

\section{INTRODUCTION}

The coronavirus pandemic presents healthcare services with unique dilemmas. Exceptionally long working hours, uncertainties and often hopelessness lead to staff feeling anxious, stressed, worried and frustrated. Data from China showed that, among 994 medical and nursing staff working in Wuhan, significant numbers of staff had subthreshold mental health disturbances. Of all participants, 36.3\% had accessed psychological materials (such as books on mental health),
$50.4 \%$ had accessed psychological resources available through media (such as online push messages on mental health self-help coping methods) and $17.5 \%$ had participated in counselling or psychotherapy. ${ }^{1}$

Social distancing measures are impacting the staff's ability to destress and cope with usual family and friends' support networks. It is more important than ever to help the National Health Service staff with their mental health and well-being. There are several online resources available; however, in practice, it is often difficult to find time and/or space to apply these. Makeshift wellbeing spaces close to clinical sites are not able to provide enough physical and by extension mental distance to focus one's mind on supporting themselves. There is disquiet and anxiety among healthcare staff as evidenced by social media posts and conversations. At the time of report submission, as far as we were aware, this was the first dedicated staff well-being hub away from the 'hot' clinical areas nationwide. Our hospital is a 560 bedded district general hospital in the SouthEast of England. The hospital employs over 4000 members of staff, including over 550 doctors.

Our aim was to provide the staff a safe, positive, 'screen free' space to realign emotional and mental energy. The staff on the way back after a stressful and busy shift may benefit from destressing in a calm environment. This will in turn enable them to give all of their positive energy and joy to their families. The mental rebalance nurtures resilience and allows people to go back and give themselves as a whole to their families. It is worth emphasising that any emotional challenge during a working life has a potentially negative impact on performance, actions, worker health and consequently on patient safety. ${ }^{2}$

We envisaged anxiety management ideas and coping strategies would be exchanged via the hub, that would lead to positive behaviour change and build 'one team' spirit through 
our hospital while allowing simultaneous casual debrief. A culture of mutual respect and care towards staff leads to horizontal communication, establishing a bond and the appreciation of a healthy work environment. ${ }^{3}$

We aim to share our project with others to allow our learning to help similar healthcare institutions. This is a dynamic, fluid, responsive and adaptive project which incorporates a continuous feedback loop and impact measurement.

\section{METHODS}

We used the continuous quality improvement methodology. The project design was registered and approved by the hospital's clinical effectiveness unit as a quality improvement project allowing us to gather anonymous feedback.

A staff survey was conducted via social media (Twitter, WhatsApp groups and Trust global email) asking if they would like a quiet space, away from clinical noise, to relax, have access to mindfulness and other calming activities. The survey had two questions only. The first question was if they felt there was a need for a staff well-being hub and the second was about what they thought was essential to have in the hub.

From our initial survey, we received 77 responses and $91 \%$ of the responders wanted a well-being hub set-up. Within our team, we managed to secure a place and used donations to hospital charity to set up the hub within a week.

The character of the hub was modelled in real time, with input, ideas and support from the attendees. The space comprises relaxed furniture, soft furnishings and inspirational messages as had been requested on the survey. Volunteers have been asked to share their hobbies, experiences and other teaching opportunities such as yoga and mindfulness sessions.

Anonymous feedback forms have been made available all the time and a repeat satisfaction survey has been conducted with attendees, 2weeks since opening. Immediate feedback was also obtained using a mood board asking for feelings before and after visit, using three emotion emojis. In addition to attendance, the level of engagement via participation in activities and volunteering was monitored.

\section{Space set-up}

The space has been intentionally set up in the Education Centre-a place geographically outside the main hospital site to allow physical and mental distancing from the clinical anxieties. It is open 24 hours a day and accessed through a staff identity badge. We do not collect staff names but do request a sign in sheet to assess the numbers using the hub and their role in the organisation. A set of rules has been displayed, requesting handwashing and social distancing in the time of COVID-19 pandemic as advised by Public Health England.
We chose to set up a dedicated, safe, screen free place for staff to destress and recuperate. We used colourful bean bags and soft furnishings. The furniture was accessorised by large green plants and floor lamps as they were requested in the initial staff survey.

We hosted structured interview sessions with members of the trust executive team, asking questions which might have otherwise remained unanswered. The questions had been collated via staff social media engagement and the speakers were invited based on the themes arising from the questions. This intervention was designed to build bridges and communication gaps. The interviewees included Director of Infection, Prevention and Control to help allay anxieties around personal protective equipment and Chief Nurse to talk about Trusts recovery plans. These sessions were recorded and uploaded on social media and Trusts YouTube channel to allow maximum reach. The safe space allows peer support and informal debrief.

Within the hub, the staff had access to board games, mindfulness activities and books. The hub is a screen free space to allow interactions or peaceful meditation (selfguided). This was requested by staff in the initial survey.

Since opening our hub, we have had contributions from local community members who have donated handmade colourful paintings. The attendees have really enjoyed viewing them and they are not only inspirational but also provide a splash of colour to the otherwise dull walls.

Various staff members have also come forward, volunteering their time to lead yoga and mindfulness sessions for staff. These are available to be prebooked allowing social distancing to be practised and have proven very popular.

We maintained a constant feedback loop through an anonymous suggestion box in the hub.

\section{RESULTS}

Since opening the hub, we have had excellent immediate feedback from staff members. People found it calming and relaxing. The space allows people to express their feelings in various manners such as using a mood board, finding another person to speak to while attending the hub. Space also allows for group activities such as games and puzzles. Attendees also found colouring therapeutic.

\section{Measurements of impact}

Number of weekly attendances

A month since the hub has been opened, 93 people have attended so far and it continues to grow in popularity as demonstrated by white board feedback and personal social media posts. On average, staff spent $33-46 \mathrm{~min}$ in the hub.

\section{Immediate feedback}

Immediate feedback is gained by visual scale of 'smilies' presession and post session:

Results from the first 4 weeks of attendees show that an increasing number of people felt their mood improved after visiting the hub (table 1 ). 


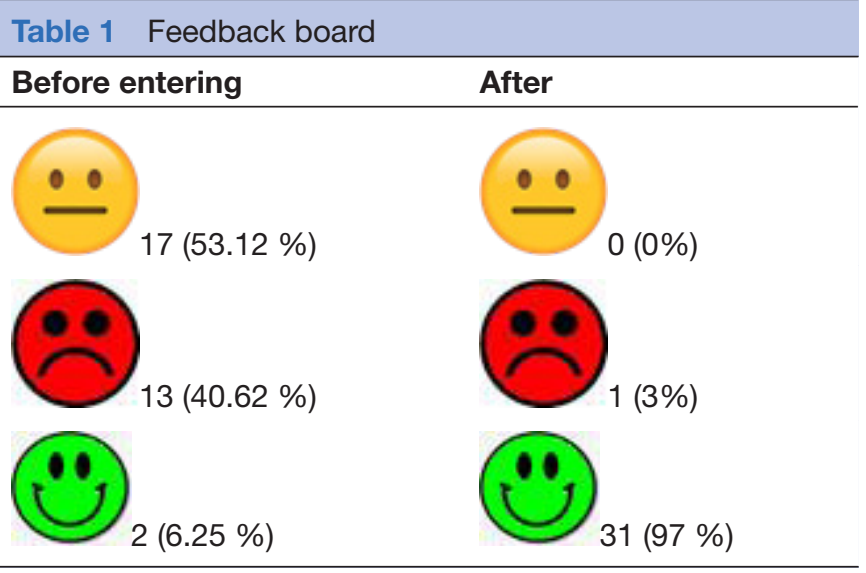

We noticed that as time passed less and less people were putting up emojis; hence, we may consider discontinuing use of this feedback.

\section{Mood board and open anonymous feedback form}

We used a white board to gauge the mood of attendees. The board is cleared every 2 weeks to allow for further expression of emotions. The board allows people to express their thoughts and worries in an anonymous fashion. In general, staff was very grateful for the space and enjoyed visiting as it was clean and tranquil. Some of the comments left by staff were as follows:

- 'Excellent space'.

- 'I went up to the Well-being hub for the first time this morning and as soon as I went in my shoulders started to drop and I had a feeling of calm and wanting to take a nap!'

- 'Love the well-being hub'.

- 'It smells serene'.

\section{Delayed feedback}

Repeat survey was sent out to staff to assess which intervention they benefited the most from.

We had 21 responses. One hundred per cent of staff who have attended love the space.

Ninety five per cent want it to stay beyond pandemic. Attendees benefitted the most from the peace and tranquillity the space offers.

\section{LIMITATIONS}

Resourcing a dedicated space away from clinical areas took a great deal of persistence and repeated efforts to highlight the need for staff well-being. The number of responses to our initial survey was small; this may in part be contributed by unprecedented clinical pressures.

Due to social distancing, we limited the number of people who could be present inside the hub simultaneously; this in turn limits the sample size of the feedback responses. To ensure the house keeping staff were visiting regularly for maintenance and sanitisation, we had to send multiple requests. This was perhaps due to increased demands on cleaning staff as they had to prioritise clinical areas.
It would have been beneficial to get feedback on mood changes following yoga sessions.

To assess if this initiative leads to a change in behaviour or organisational change, further staff surveys will need to be conducted.

\section{DISCUSSION}

During the COVID-19 pandemic, there was a national drive to focus on the well-being of National Health Service Staff. A lot of the initiatives were focused on getting right help to people who need it the most. Several online apps waived their charges, psychiatrists volunteered their time and online sessions were delivered by experts. In setting up the hub, we followed guidance from the national bodies and crucially placed the importance of staff engagement at a local level. The space has been cocreated, designed and delivered with continuous staff engagement. It is a responsive and adaptable set-up.

The vision was to develop a space that addresses local needs. Hence, we used the continuous quality improvement methodology. People are more likely to use a resource that has involved them in the set-up and design. The high number of attendances and highly positive feedback has reinforced our belief. The space also allows for peer support and casual debrief. Data suggest that relaxed, reflective group debrief cultivates relational connection, enables offloading of the burdens associated with caring and guides reflective 'work on work'.

We feel this hub will continue to be a source of calm for attendees and provide for a space where people will feel safe expressing their feelings. The ongoing presence of the hub will make them feel cared for while at work as we enter the recovery phase of the current pandemic.

Twitter Aaisha Saqib @Aaisha_Saqib

Acknowledgements The authors will like to acknowledge Edyta Mccallum, Alex Hayes, Donna Law, Julie Stoppani, Nina Lee and Michael Addley for all their help with hub set-up.

Contributors I can confirm that both authors contributed towards the development and implementation of the hospital-wide project and contributed to authorship of the article. AS: led the surveys, helped set up the hub and collate data. TR: project design and engaging other stakeholders.

Funding The authors have not declared a specific grant for this research from any funding agency in the public, commercial or not-for-profit sectors.

Competing interests None declared.

Patient and public involvement Patients and/or the public were not involved in the design, or conduct, or reporting, or dissemination plans of this research.

Patient consent for publication Not required.

Provenance and peer review Not commissioned; externally peer reviewed. Data availability statement All data relevant to the study are included in the article.

Open access This is an open access article distributed in accordance with the Creative Commons Attribution Non Commercial (CC BY-NC 4.0) license, which permits others to distribute, remix, adapt, build upon this work non-commercially, and license their derivative works on different terms, provided the original work is properly cited, appropriate credit is given, any changes made indicated, and the use is non-commercial. See: http://creativecommons.org/licenses/by-nc/4.0/.

ORCID iD

Aaisha Saqib http://orcid.org/0000-0003-4424-7681 


\section{REFERENCES}

1 Zhang J, Lu H, Zeng $\mathrm{H}$, et al. The differential psychological distress of populations affected by the COVID-19 pandemic. Brain Behav Immun 2020;87:49-50.

2 Littlejohn P. The missing link: using emotional intelligence to reduce workplace stress and workplace violence in our nursing and other health care professions. J Prof Nurs 2012;28:360-8.
3 Oliveira RM, Silva LMSda, Guedes MVC, et al. Analyzing the concept of disruptive behavior in healthcare work: an integrative review. Rev Esc Enferm USP 2016;50:695-704.

4 Hunt SL. Reflective debrief and the social space: offload, refuel, and stay on course. Clin Radiol 2020;75:265-70. 